\title{
Perceptions of Kinesiophobia in Relation to Physical Activity and Exercise After Myocardial Infarction: A Qualitative Study
}

Maria Bäck, Victoria Caldenius, Leif Svensson and Mari Lundberg

The self-archived postprint version of this journal article is available at Linköping University Institutional Repository (DiVA):

http://urn.kb.se/resolve?urn=urn:nbn:se:liu:diva-173199

N.B.: When citing this work, cite the original publication.

Bäck, M., Caldenius, V., Svensson, L., Lundberg, M., (2020), Perceptions of Kinesiophobia in Relation to Physical Activity and Exercise After Myocardial Infarction: A Qualitative Study, Physical Therapy, 100(12), 2110-2119. https://doi.org/10.1093/ptj/pzaa159

Original publication available at:

https://doi.org/10.1093/ptj/pzaa159

Copyright: American Physical Therapy Association (APTA)

http://www.apta.org/ 


\section{Perceptions on kinesiophobia in relation to physical activity and exercise after myocardial infarction - a qualitative study}

Bäck M, PT, Associate Professor ${ }^{1,2}$, Caldenius V, PT, MSc ${ }^{3}$, Svensson L, MD, Professor ${ }^{4}$ Lundberg M, PT, Professor 5,6

${ }^{1}$ Department of Health, Medicine and Caring Sciences, Division of Prevention, Rehabilitation and Community Medicine, Unit of Physiotherapy, Linköping University, Linköping, Sweden. E-mail: maria.back@liu.se

${ }^{2}$ Department of Occupational Therapy and Physiotherapy, Sahlgrenska University Hospital, Gothenburg, Sweden. E-mail: maria.m.back@vgregion.se

${ }^{3}$ Previa, Occupational Healthcare Service, Stockholm, Sweden. E-Mail: victoria.caldenius@previa.se

${ }^{4}$ Department of Medicine, Karolinska Institutet, Stockholm, Sweden. E-mail: leif.svensson@ki.se

${ }^{5}$ Division of Physiotherapy, Department of Health and Rehabilitation, Institute of Neuroscience and Physiology, University of Gothenburg, Gothenburg, Sweden. E-mail: mari.lundberg@gu.se

${ }^{6}$ Division of Physiotherapy, Department of Neurobiology, Care Sciences and Society, Karolinska Institutet, Stockholm, Sweden

Corresponding author:

Maria Bäck, PT, Associate Professor, Linköping university, Department of Health, Medicine and Caring Sciences, Division of Prevention, Rehabilitation and Community Medicine, Unit of Physiotherapy, S-581 83 Linköping, Sweden, E-mail: maria.back@liu.se 


\begin{abstract}
Background

Physical activity and exercise are central components in the rehabilitation after a myocardial infarction. Kinesiophobia (fear of movement) is a well-known barrier for a good rehabilitation outcome in these patients, however, there is a lack of studies focusing on the patients' perspective.
\end{abstract}

\title{
Objective
}

The aim was to explore patients' perceptions of kinesiophobia in relation to physical activity and exercise two to three months after an acute myocardial infarction.

\section{Design}

Qualitative study design with individual semi-structured interviews.

\section{Methods}

Face-to-face interviews were conducted with 21 patients post-myocardial infarction, who have been screened for kinesiophobia ( $\geq 32$ on the Tampa Scale for Kinesiophobia Heart). The interviews were transcribed and analyzed according to an inductive content analysis.

\section{Results}

An overarching theme was defined as "Coping with fear of movement after a myocardial infarction - a dynamic process over time" comprising two sub-themes, explaining how coping with kinesiophobia runs in parallel processes integrating the patient's internal process and a contextual external process. The two processes are described in a total of eight categories. The internal process was an iterative process governed by a combination of factors; Ambivalence, Hypervigilance, Insecurity about progression, Avoidance behavior. The external process contains the categories; Relatives' anxiety, Prerequisites for feeling safe, Information, The exercise-based cardiac rehabilitation program. 


\section{Conclusion}

To cope with fear of movement after a myocardial infarction is a dynamic process that requires internal and external support. To further improve cardiac rehabilitation programs, person-centered strategies that supports the process of each person as well as the development of new treatment strategies in order to reduce kinesiophobia needs to be elaborated.

\section{Impact statement:}

As patients having suffered a myocardial infarction were found to be ambivalent about how they expressed their fear of movement, it is crucial that physical therapists can acknowledge signs of fear, by listening carefully to the patient's full story, in addition to the use of adequate self-reports and tests of physical fitness. The results are important in the future design to develop and evaluate new treatment strategies, with the overall aim of reducing kinesiophobia and increasing physical activity and participation in exercise-based CR.

Word count: 4440 


\section{Introduction}

Cardiovascular disease, including acute myocardial infarction, is causing a large proportion of disability and death, placing a substantial burden on the health care systems and economies $^{1}$. In the secondary prevention after myocardial infarction, cardiac rehabilitation (CR) is recommended ${ }^{2,3}$. CR comprises comprehensive multidisciplinary interventions, with physical activity counselling and exercise as central components ${ }^{3,4}$. Meta-analyses clearly confirm the benefits of exercise-based CR in terms of reduced cardiac mortality, risk of hospital admission ${ }^{2}$, as well as positive effects on oxygen uptake, and psychological wellbeing ${ }^{5,6}$. Although $\mathrm{CR}$ as treatment post-myocardial infarction is highly recommended ${ }^{3,4}$, the current underuse is a matter of concern ${ }^{7}$.

Experiencing an acute myocardial infarction can be frightening and traumatic and may become an existential threat that triggers a chain reaction, resulting in the transformation of patients' priorities and perspectives in life ${ }^{8,9}$. Psychosocial factors including anxiety, depression, hostility and social isolation are common in patients with coronary artery disease. Up to $40 \%$ of these patients experience symptoms of anxiety and depression ${ }^{10}$, contributing to independent risk factors for cardiac mortality and morbidity ${ }^{11,12}$. More recently several patients with cardiac disease have been identified to be fearful of physical activity and exercise after an acute coronary event ${ }^{13,14}$. In the acute stages following an acute myocardial infarction, fear and associated avoidance behaviors are typical psychological reactions. However, patients who are unable to cope with their fear may develop kinesiophobia ${ }^{15}$. According to the underlying theoretical framework fear of movement in combination with catastrophizing thoughts lead to a maladaptive avoidance behavior, causing negative health consequences, such as physical inactivity, disability and depression ${ }^{16,17}$. We have previously shown that kinesiophobia was present in $20 \%$ of patients with coronary artery disease at six 
months follow-up after their coronary event ${ }^{13}$. This result was confirmed in a longitudinal design, showing the proportion of patients with occurrence of kinesiophobia to be highest in the acute cardiac care unit (25\%) and decreased and stabilized at follow-up after two weeks $(19 \%)$ and at four to six months $(21 \%){ }^{14}$ Moreover, the occurrence of kinesiophobia had a negative influence on clinical variables important to rehabilitation outcomes and prognosis in the secondary prevention of coronary artery disease, including lower levels of physical activity and reduced attendance at exercise-based CR ${ }^{13}$.

There is, however, a lack of studies focusing primarily on patients' perceptions of kinesiophobia in relation to physical activity and exercise after a myocardial infarction. Qualitative methods can complement existing knowledge in this field by giving a greater understanding into the patients' perceptions of the phenomenon ${ }^{18}$. It is important to understand kinesiophobia from the patient's perspective, in order to adjust assessment and treatment interventions accordingly. Therefore, the aim of the study was to explore patients' perceptions of kinesiophobia in relation to physical activity and exercise two to three months after an acute myocardial infarction.

\section{Method}

\section{Study design}

The study was set up as a qualitative study design with individual semi-structured interviews, analyzed according to content analysis with an inductive approach ${ }^{19}$.

\section{Qualitative approach and research paradigm}

The inductive conventional approach of content analysis was used, in which coding categories are derived directly from the text data, with the advantage of gaining direct 
information from the patients without imposing preconceived categories or theoretical perspectives ${ }^{20}$. Qualitative content analysis is further divided into latent and manifest content analysis. Latent content analysis implies encoding and interpretation of the underlying meaning of the text ${ }^{19,21}$.

\section{Patients}

Patients who had suffered from a myocardial infarction and who had been hospitalized at the cardiac intensive care unit (CCU) at one of the largest hospitals in Stockholm, Sweden were asked to participate in the study. Inclusion criteria were a principal diagnosis of myocardial infarction and a value of $\geq 32$ on the Tampa Scale for Kinesiophobia Heart (TSK-SV Heart)

${ }^{22}$. The exclusion criteria were an inability to speak or understand the Swedish language, serious psychiatric or somatic disease interfering with participation, and marked limitation in physical activity due to diagnosis of heart failure corresponding to New York Heart Association Functional Classification category III or worse.

The intention was to include 20 patients, as this was considered appropriate in order to capture common patterns and unique variations within a study of this type and scope.

\section{Setting}

The setting in this study followed the three main phases of a CR programme that are considered to be conventional care ${ }^{4}$. Phase I is typically an inpatient service, which consists of early mobilisation, counselling about risk factor management and follow-up planning. Phase II is mainly a supervised ambulatory outpatient CR programme. Phase III is a lifetime maintenance phase where the goal is to continue the risk factor- and lifestyle change, including physical activity and exercise. 


\section{Inclusion procedure}

Physical therapists working at the CCU informed eligible patients about the study during their stay at the hospital. Those who accepted to participate in the study went through the procedure described below. The regional ethical review board in Stockholm approved the study protocol (Registration number: 2013/1309-31/3) and all patients gave their informed consent prior to participation.

The TSK-SV Heart was sent out by ordinary post to the patients six weeks after their discharge from hospital. In all, 160 patients were asked about participation. Among these, 127 agreed to participate. Twenty-five patients scored $\geq 32$ on the TSK-SV Heart and were invited to be interviewed. Four out of the 25 patients could not be reached or did not show up at the scheduled time, giving 21 persons left to interview. For a detailed description of the inclusion procedure see Figure 1. Descriptive characteristics are described in Table 1.

\section{In-depth interview procedure}

In-depth face-to-face interviews were performed between December 2013 and May 2014 and the analyses were performed during August 2014 and August 2019. The interviews were performed two to three months after patients' acute myocardial infarction. The patients were interviewed by a physical therapist with extensive clinical experience of working with exercise-based CR (VC). All interviews started with the same opening question "How did you experience to move after having suffered a myocardial infarction?". The interviews had a semi-structured focus, based on an interview guide (Appendix). Follow-up questions were used, aimed to further deepen the dialogue. Two pilot interviews were performed to test the interview guide. The interview guide remained unchanged, but the interview technique was refined. The pilot studies were included in the analyses. The interviews were performed in a 
location chosen by the participant (e.g. private room at the hospital or the patient's home). The interviews lasted for a median of 48 minutes ( $\min 27$ to max 65 minutes) and were recorded digitally.

Description of the research group involved in the analyses

In order to facilitate a broad understanding of the phenomenon under study we combined several competencies and experiences in the research group. The main author Maria Bäck (MB) contributed with a combination of clinical experience as a physical therapist and research experience from the patient group and the field of kinesiophobia. MB was not involved with the patients' care and rehabilitation. Victoria Caldenius (VC) was the person who performed the interviews. VC has clinical experience of working with this type of patient group. Leif Svensson (LS) is an experienced cardiologist and researcher within the field of cardiology. Mari Lundberg (ML) contributed with skills in qualitative research methodology and in-depth knowledge of the phenomenon kinesiophobia.

\subsection{Analysis}

\section{Data processing}

All data was coded according to the subject ID given at the inclusion of the study. Thereafter only the principal investigator had access to the key to identify the patient. All files (sound and words) were stored according to the ethical codes and Swedish law. The interviews were transcribed by VC.

\section{Data analysis}


The transcripts of the interviews were analyzed in an iterative process according to an inductive content analysis inspired by Graneheim and Lundman ${ }^{19}$, as described in Table 2. We described the manifest content and interpreted the latent message.

Insert Table 2 about here. The content analytic procedure as applied in this study, inspired by Graneheim and Lundman (Graneheim and Lundman 2004).

Techniques to achieve trustworthiness and credibility of data analysis

In order to enhance trustworthiness and credibility of data analysis, a procedure was planned a priori. $\mathrm{VC}$ and $\mathrm{MB}$ analyzed all the interviews from step 1 to step 4. ML gave methodological support during the process. At Steps 5 to $6 \mathrm{ML}$ joined the analyses, and all the authors worked to define themes and subthemes until consensus was achieved. This stage was an iterative process, which was refined at several meetings. The trustworthiness of the analysis was guaranteed by means of a second analysis from step 1 to 4 by the last author (ML). Finally, comparisons were made between the analyses performed by (MB, VC and ML). To increase credibility, triangulation was used during the analysis, seeking agreement among all co-researchers and, in addition, representative quotations from the transcribed text are presented.

\section{Results}

One overarching theme emerged from the analysis, "Coping with fear of movement after a myocardial infarction - a dynamic process over time". All patients have been screened for elevated score on the TSK-SV Heart since it was part of the purpose to explore the patients' experiences of kinesiophobia. They all had experienced a trauma (their acute myocardial 
infarction) and the interviews were performed two to three months after their trauma, and their experiences are to be understood in that context.

The overarching theme comprises two sub-themes, explaining how to cope with fear of movement runs parallel iterative processes integrating the patient's internal process and $a$ contextual external process. The details of these processes are described in a total of eight categories.

\section{The patient's internal process}

How the patients cope with their fear of movement is partly reflected in a dynamic internal process. Patients describe how they reason with themselves about how to handle their fear as their recovery period moves on. The internal process is an iterative process governed by a combination of factors, described in detail in the categories below; Ambivalence, Hypervigilance, Insecurity about dose and progression of physical activity and exercise, Avoidance behavior

\section{Ambivalence}

Fear of movement was evident for all patients directly after the myocardial infarction. The fear of movement remained to some extent over time, and the patients expressed an ambivalent approach to fear of movement. On the one hand, patients stated that they were not afraid, but on the other hand, they still expressed concern about the risk of suffering another myocardial infarction by conducting different physical activities. Patients objected to the word "fear" and would rather refer to themselves as "cautious". 
"Yes, but then I am not as scared now as I was before, but at the same time it is that Ifeel this, there is always a sense of something that has happened that makes me feel a little uncertain as to what you can do and not do "3.5

Hypervigilance

Experiencing a myocardial infarction has made patients more sensitive to their body signals. Patients could express an increased concern related to physical activity, as several of the symptoms they experienced during physical activity/exercising felt similar to the incidence of the myocardial infarction. Some manage to cope in an adequate way with their symptoms, while for others the symptoms trigger fear of movement. A commonly used coping strategy to handle fear of bodily symptoms was to pace and rest.

"I had been out on one of my walks and then I felt a stab in the back, it was really so bad that I almost had to stop and walk very slowly. Then you get scared. Every time something happens, I get scared. So, I take it easy, just try to take it easy and hope that it does not develop into what it was that made me have to go in by ambulance "3.9

Insecurity about dose and progression of physical activity and exercise Patients described uncertainty about type and dose of physical activity and exercise in relation to fear of overstraining the heart. Patients expressed, that over time, they wanted to increase the dose of physical activity and exercise, but they felt insecure about how and when to do it. Commonly patients felt insecurity about performing unsupervised physical activities/exercises, or things they had not tried under safe conditions. Patients could describe that they tried to challenge themselves and gradually progress physical activity and exercise by exploring and pushing their limits. 
"I am very scared when I'm going to vacuum my big thick mat under the living room table, how forceful can I be with the vacuum cleaner when vacuuming my wool mat? I don't want to use the vacuum cleaner because I don't know if I can handle it. 21.25

"I have no idea if it is suitable to lift as much as I can or if I should have done that 14 days ago. I can't judge when it's time to raise the bar and start lifting. You have to start exploring a little yourself... "2.19

"After having participated in the exercise-based cardiac rehab group for a while, I booked a class on a boxing pass. Then I got scared because I thought how hard can I exercise here? It is still quite a tough class so I tried to fake a little so it looked like I had worse condition because I did not dare really, because I had not exercised at maximum heart rate ... " 8.6

\section{Avoidance behavior}

Some patients described fear and avoidance behavior regarding everyday activities such as lifting, carrying and vacuuming, while others experienced fear of more strenuous activities such as walking uphill, climbing stairs or dancing. Patients could express how they tried to confront their fear, by gradually trying the activities they feared. Others, however, got stuck in a more permanent avoidance behavior avoiding many different activities that they previously used to value highly. Their behavior was guided by beliefs about saving the heart. The fear could be so strong that it led to an extensive avoidance behavior, where the patient did not leave the house in fear of having a new myocardial infarction. What to avoid and what not to avoid is vague to the patients and could be guided by beliefs and catastrophizing thoughts. 
"I like to knit, but I pause now. I don't know if I can. I used to knit a lot but not now, maybe half an hour a day, no more. Before, I could knit for several hours, but not now. It is an example of me being careful " 5.25

"The most drastic thing is to dive from the high dive. The fantasy I get then is that it is such a shock to the heart that it stops. That's what my girlfriend is so scared of, if I don't get out of the water, that it is fatal, but maybe it is an excessive fear? I don't know, I haven't even asked any doctor about it "'18.22

\section{A contextual external process}

The external process is run in parallel to the internal process and they both interplay and influences how patients cope with their fear of movement. The external process contains the following categories; Relatives' anxiety, Prerequisites for feeling safe, Information, The exercise-based cardiac rehabilitation program

\section{Relatives' anxiety}

Not only does the patient's own fear gear the physical activity and exercise behavior, but so does also the relatives' anxiety and concern. The patients described how the relatives could prevent and discourage them from doing different types of activities, such as vacuum cleaning, baking or going for a walk. Patients could perceive this as frustrating, causing even more insecurity on how to behave in relation to physical activity. Some even described a loss of identity, not being able to be the one they wanted to be. Patients could adapt to the advice, while others relied on their own knowledge and experience. 
"Someone said that you should not raise your hands above your head. So, the third day when I'm home, my son called and wondered what I had done today. I answered, that I had unloaded the dishwasher. Oh, he said, you should not lift your hands above the head. I thought I had done something good, but I obviously hadn't'. 12.24

"Then a sad thing. In the past, I used to always do floor cleaning at my sweetheart's home where she lives. I vacuumed and moped the floor and it is actually a very strenuous activity. So, after this myocardial infarction, my girlfriend insisted that I have to stop that. It feels like a loss to me. I was a little proud to take care of that, but it's one activity I think is too strenuous now"18.19

\section{Prerequisites for feeling safe}

Patients described different external prerequisites and strategies for feeling safe to perform physical activities and exercise. These included bringing their nitroglycerin spray or phone with them, having company of someone during an activity, and performing the activity near home to feel safe.

"My wife did not let me out alone, but she accompanied me and we walked in the immediate area so it was close, and I had nitroglycerin with me "13.6

"It is important when you are doing things that you know that there may be someone or a cell phone nearby, also you may think a little more so that there is either something like that there. But now I have gotten into that idea of always having nitroglycerin wherever I go and make sure that it is nearby, only when you get into that thinking you need not feel any fear of pain "15.35 


\section{Information}

Patients described information as a central component for their coping process after the myocardial infarction. They described how the information from the hospital, relatives and society in different ways increased or reduced their fear of movement. Patients could describe that if the information was perceived as adequate it helped them to challenge their limits related to physical activity and exercise. In cases where the information from the hospital was mainly perceived as unclear, non-consistent or insufficient it created uncertainty and increased fear of movement. Patients described that both the content as well as how the information was delivered was important factors. Information from the surrounding community such as reporting on sudden cardiac arrest from sports events has created concern and uncertainty about how safe it is for the heart to exercise.

"I do not know what exertion does with my body, I have not received that information, what happens to my body if I carry two food bags? If I go out and walk fast so I feel my heart beating, what happens then? Nobody talked about it to me, still no one has talked about it to me. There is no information when you get home about anything, but you are sent to the cardiac rehabilitation and a lot of examinations, but still no one sits down and says: How are you? Do you have any questions? 21:20

\section{The exercise-based cardiac rehabilitation program}

Patients expressed that participation at exercise-based CR could help them cope with their fear of movement, by means of concrete interventions such as performing a supervised exercise test, receiving an individually adapted exercise program, learning how to adjust exercise using the Borg's perceived exertion scale ${ }^{23}$ and exercising with peers sharing similar 
experiences. They clearly indicate the gap between exercising at the hospital as compared to doing it home. On the other hand, cardiac rehabilitation could also be described as stressful and that the mode and setting did not fit them.

"I have been offered physiotherapy, but then it was actually so that at the last moment I backed out and did not dare. That was because I found out what they thought I would do. I would come and sit on an ergometer cycle and pedal, and then I received a horror vision of sitting on the bike and then maybe some energetic physiotherapist would think that I did not cycle fast enough and she would want me to do more and more "18.27

"In the beginning, I felt that it was so heavy on the bike and I got a very increased heart rate and so I thought it cannot be good. But then I started thinking that you (physiotherapist) have done this a thousand times with people who have had a myocardial infarction.... I still think it is damn heavy to bicycle, but I am not afraid of it". 17.42

"At home I am a little more careful, here (CR) I relax and exercise properly, but at home I am more careful. Here I am completely relaxed. I exercise properly, no cheating. But at home I think and cheat more, how far is it when I go shopping. Here you relax "5.41

\section{Discussion}

In this study, we explored patients' perceptions of kinesiophobia in relation to physical activity and exercise two to three months after a myocardial infarction. One overarching theme emerged from the analysis, which could be summarized as "Coping with fear of movement after a myocardial infarction - a dynamic process over time". In this discussion we will try to disentangle the clinical relevance of these results. 
The patients clearly expressed an internal coping process, in which they struggled to cope with the fear along with their recovery, and their stories unravel things usually hard for us healthcare professionals to capture. All patients in this study were included based on kinesiophobic thoughts. Even so, in the category Ambivalence, it was clear that the word fear was not necessarily used but might be hidden in the wording of cautious. So, as health care professionals, we need to listen carefully to the wordings and follow-up on what the words mean to the patient. The importance of building partnership and to listen is the essence of person centeredness and its' relevance is growing within physical therapy ${ }^{24}$.

According to guidelines, it is important that exercise-based CR programs are individually prescribed and continuously progressed according to the physical fitness level of each patient to achieve the optimal effects from exercise ${ }^{3,4,25}$. From our interviews, we found that patients prefer advice that are specifically tailored to their needs, as opposed to a more general information. This is consistent with the European guideline on cardiovascular disease prevention ${ }^{26}$, stating that a person-centered communication and shared decision-making between the patient and health care professional is considered the basis for a successful and trustful relation. It has been shown to be a powerful source of emotional support and professional guidance in coping with psychosocial stressors in patients with cardiovascular disease ${ }^{27}$.

Patients in the present study could perceive that non-consistent and unclear information about physical activity and exercise increased their fear of movement. This is in line with previous studies in patients with chronic pain, showing that fear of movement may be fed by health care providers' own perceptions of how harmful activity can be ${ }^{28,29}$. Moreover, it is 
important to include relevant information about heart disease to relatives and to integrate partners in interventions to provide emotional support and to help the patient manage the disease ${ }^{26}$. This is highly significant, as patients in the present study express frustration that relatives could discourage them from participating in different physical activities, leading to increased fear. At last, guidelines strongly recommend that all health care professionals provide consistent information ${ }^{4,26}$.

Patients in our study expressed that they had become more sensitive to body signals, which they perceived as threatening, because of the life-threatening trauma that the myocardial infarction meant to them. Hypervigilance has been described as an important aspect of the cognitive fear-avoidance model of pain, showing that catastrophizing, fear, and anxiety of pain are related to hypervigilance, and hypervigilance is related to disability ${ }^{30,31}$. The patients in the current study described how the hypervigilance made them tend to avoid physical activity and exercise, and instead lean towards rest. This is also confirmed in a previous study, where patients with coronary artery disease felt hesitant to exercise when they experienced increased heart rate and shortness of breath, fearing that these reactions were signs that their heart were in danger ${ }^{9}$.

A potential limitation of the study may be the gap in time between recruitment and analysis.

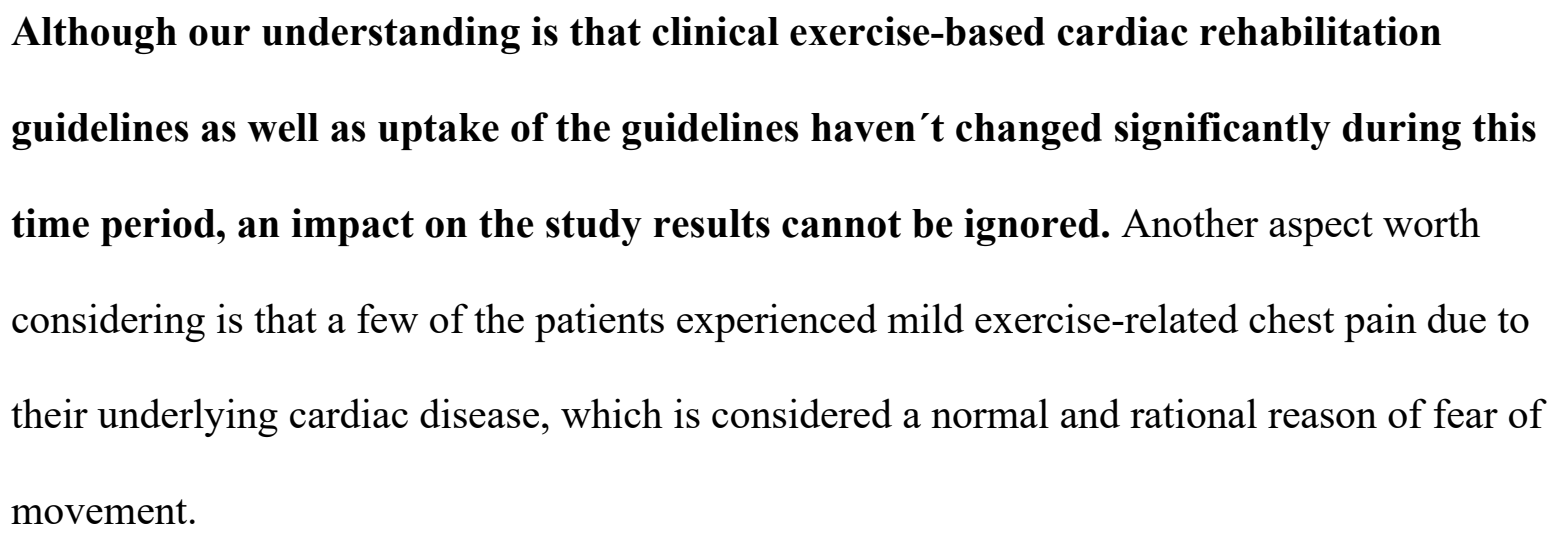


To move forward, evidence-based treatment strategies for patients identified with kinesiophobia are suggested. Interventions to mitigate kinesiophobia have not been extensively studied in patients with myocardial infarction, however, the principles of graded exercise is partly already applied in current exercise-based CR programs ${ }^{32,33}$. These programs must, however, be further adapted for the assessment and treatment of kinesiophobia. Effective treatment strategies, based on cognitive-behavioral techniques, has been shown to be effective for reducing disabling fear and anxiety in other conditions ${ }^{32,34-36}$. This intervention targets fear-avoidance beliefs as well as self-efficacy which are regarded as important for a person's ability to remain active despite the feared event, for example pain or fear of a recurrent cardiac event ${ }^{35,37}$. Future studies should address the optimal treatment of kinesiophobia in patients having suffered a myocardial infarction.

\section{Methodological considerations}

A crucial aspect of all research is to be able to trust the data, and credibility refers to confidence in how well data and processes of analysis address the intended focus ${ }^{38}$. One aspect of credibility is how the participants were selected, which is thoroughly described in the method section. Moreover, credibility is about selecting the most appropriate method for data collection ${ }^{19}$ and we would argue that face-to-face in-depth interviews is the most appropriate method for the purpose of the current study. Another aspect of credibility is how the meaning units were selected and how the subsequent analytic steps were performed. In our study, we addressed this issue, by building a triangulation procedure (see method). To facilitate transferability, we have given a clear and distinct description of culture and context, data collection and process of analysis, as well as a rich and vigorous presentation of the findings together with appropriate quotations. 


\section{Conclusion}

This study demonstrates that patients with kinesiophobia, after having experienced a trauma in terms of an acute myocardial infarction, cope with their fear in a dynamic iterative process over time, including both internal and external factors of importance. Patients were found to be ambivalent about how they expressed their fear of movement. It is therefore of importance that physical therapists can acknowledge signs of fear, by listening carefully to the patient's full story, in addition using adequate self-reports and tests of physical fitness. The results of this study can be used to increase awareness of kinesiophobia in a cardiovascular context, and in the future design to develop and evaluate new treatment strategies, with the overall aim of reducing kinesiophobia and increasing physical activity and participation in exercise-based CR.

Conflict of Interest: none declared 


\section{References}

1. Timmis A, Townsend N, Gale CP, et al. European Society of Cardiology: Cardiovascular Disease Statistics 2019. Eur Heart J. Jan 1 2020;41(1):12-85.

2. Anderson L, Thompson DR, Oldridge N, et al. Exercise-based cardiac rehabilitation for coronary heart disease. Cochrane Database Syst Rev. 2016;1:CD001800.

3. Ambrosetti M, Abreu A, Corra U, et al. Secondary prevention through comprehensive cardiovascular rehabilitation: From knowledge to implementation. 2020 update. A position paper from the Secondary Prevention and Rehabilitation Section of the European Association of Preventive Cardiology. Eur J Prev Cardiol. Mar 30 2020:2047487320913379.

4. Piepoli MF, Corra U, Adamopoulos S, et al. Secondary prevention in the clinical management of patients with cardiovascular diseases. Core components, standards and outcome measures for referral and delivery: a policy statement from the cardiac rehabilitation section of the European Association for Cardiovascular Prevention \& Rehabilitation. Endorsed by the Committee for Practice Guidelines of the European Society of Cardiology. Eur J Prev Cardiol. Jun 2014;21(6):664-681.

5. Lawler PR, Filion KB, Eisenberg MJ. Efficacy of exercise-based cardiac rehabilitation post-myocardial infarction: a systematic review and meta-analysis of randomized controlled trials. Am Heart J. Oct 2011;162(4):571-584 e572.

6. Verschueren S, Eskes AM, Maaskant JM, Roest AM, Latour CHM, Op Reimer WS. The effect of exercise therapy on depressive and anxious symptoms in patients with ischemic heart disease: A systematic review. J Psychosom Res. Feb 2018;105:80-91.

7. Kotseva K, Wood D, De Bacquer D, investigators E. Determinants of participation and risk factor control according to attendance in cardiac rehabilitation programmes in coronary patients in Europe: EUROASPIRE IV survey. Eur J Prev Cardiol. Jan 1 2018:2047487318781359.

8. Back M, Oberg B, Krevers B. Important aspects in relation to patients' attendance at exercise-based cardiac rehabilitation - facilitators, barriers and physiotherapist's role: a qualitative study. BMC Cardiovasc Disord. Mar 14 2017;17(1):77.

9. Simony CP, Pedersen BD, Dreyer P, Birkelund R. Dealing with existential anxiety in exercise-based cardiac rehabilitation: a phenomenological-hermeneutic study of patients' lived experiences. J Clin Nurs. Sep 2015;24(17-18):2581-2590.

10. Hagstrom E, Norlund F, Stebbins A, et al. Psychosocial stress and major cardiovascular events in patients with stable coronary heart disease. J Intern Med. Jan 2018;283(1):83-92.

11. Lichtman JH, Froelicher ES, Blumenthal JA, et al. Depression as a risk factor for poor prognosis among patients with acute coronary syndrome: systematic review and recommendations: a scientific statement from the American Heart Association. Circulation. Mar 25 2014;129(12):1350-1369.

12. Watkins LL, Koch GG, Sherwood A, et al. Association of anxiety and depression with all-cause mortality in individuals with coronary heart disease. $J$ Am Heart Assoc. Mar 19 2013;2(2):e000068.

13. Back M, Cider A, Herlitz J, Lundberg M, Jansson B. The impact on kinesiophobia (fear of movement) by clinical variables for patients with coronary artery disease. Int J Cardiol. Jul 31 2013;167(2):391-397.

14. Back M, Lundberg M, Cider A, Herlitz J, Jansson B. Relevance of Kinesiophobia in Relation to Changes Over Time Among Patients After an Acute Coronary Artery Disease Event. J Cardiopulm Rehabil Prev. Jul 2018;38(4):224-230. 
15. Kori SH, Miller RP, Todd DD. Kinesiophobia: a new way of chronic pain behavior. Pain Management 1990;3:35-43.

16. Vlaeyen JW, Kole-Snijders AM, Boeren RG, van Eek H. Fear of movement/(re)injury in chronic low back pain and its relation to behavioral performance. Pain. Sep 1995;62(3):363-372.

17. Crombez G, Eccleston C, Van Damme S, Vlaeyen JW, Karoly P. Fear-avoidance model of chronic pain: the next generation. Clin J Pain. Jul 2012;28(6):475-483.

18. Krippendorff K. Content analysis : an introduction to its methodology. Thousand Oaks, Calif. ;: SAGE; 2013.

19. Graneheim UH, Lundman B. Qualitative content analysis in nursing research: concepts, procedures and measures to achieve trustworthiness. Nurse Educ Today. Feb 2004;24(2):105-112.

20. Hsieh HF, Shannon SE. Three approaches to qualitative content analysis. Qual Health Res. Nov 2005;15(9):1277-1288.

21. Downe-Wamboldt B. Content analysis: method, applications, and issues. Health Care Women Int. Jul-Sep 1992;13(3):313-321.

22. Back M, Jansson B, Cider A, Herlitz J, Lundberg M. Validation of a questionnaire to detect kinesiophobia (fear of movement) in patients with coronary artery disease. $J$ Rehabil Med. Apr 2012;44(4):363-369.

23. Borg G. Borg's Perceived exertion and pain scales. Champaign, Ill.: Human Kinetics; 1998.

24. Lundberg M. Physiotherapists need to engage in a person-centred ethics for better health. Eur J Physiother. 2019:65-66.

25. Katch VL, Katch VL, McArdle WD, Katch FI, McArdle WD. Essentials of exercise physiology. Philadelphia: Wolters Kluwer/Lippincott Williams \& Wilkins Health; 2011.

26. Piepoli MF, Hoes AW, Agewall S, et al. 2016 European Guidelines on cardiovascular disease prevention in clinical practice: The Sixth Joint Task Force of the European Society of Cardiology and Other Societies on Cardiovascular Disease Prevention in Clinical Practice (constituted by representatives of 10 societies and by invited experts)Developed with the special contribution of the European Association for Cardiovascular Prevention \& Rehabilitation (EACPR). Eur Heart J. Aug 1 2016;37(29):2315-2381.

27. Albus C, Waller C, Fritzsche K, et al. Significance of psychosocial factors in cardiology: update 2018 : Position paper of the German Cardiac Society. Clin Res Cardiol. Nov 2019;108(11):1175-1196.

28. Houben RM, Ostelo RW, Vlaeyen JW, Wolters PM, Peters M, Stomp-van den Berg SG. Health care providers' orientations towards common low back pain predict perceived harmfulness of physical activities and recommendations regarding return to normal activity. Eur J Pain. Apr 2005;9(2):173-183.

29. Linton SJ, Vlaeyen J, Ostelo R. The back pain beliefs of health care providers: are we fear-avoidant? J Occup Rehabil. Dec 2002;12(4):223-232.

30. Vlaeyen JW, Linton SJ. Fear-avoidance and its consequences in chronic musculoskeletal pain: a state of the art. Pain. Apr 2000;85(3):317-332.

31. Shigetoh H. Hypervigilance to pain affects activities of daily living: an examination using the Japanese version of the pain vigilance awareness questionnaire. $J$ Phys Ther Sci. Dec 2017;29(12):2094-2096.

32. Fordyce WE, Fowler RS, Jr., Lehmann JF, Delateur BJ, Sand PL, Trieschmann RB. Operant conditioning in the treatment of chronic pain. Arch Phys Med Rehabil. Sep 1973;54(9):399-408. 
33. Lindstrom I, Ohlund C, Eek C, et al. The effect of graded activity on patients with subacute low back pain: a randomized prospective clinical study with an operantconditioning behavioral approach. Phys Ther. Apr 1992;72(4):279-290; discussion 291-273.

34. George SZ, Wittmer VT, Fillingim RB, Robinson ME. Comparison of graded exercise and graded exposure clinical outcomes for patients with chronic low back pain. J Orthop Sports Phys Ther. Nov 2010;40(11):694-704.

35. Vlaeyen JWS. Pain-related fear : exposure-based treatment for chronic pain. Seattle: IASP Press; 2012.

36. Vlaeyen JW, Linton SJ. Fear-avoidance model of chronic musculoskeletal pain: 12 years on. Pain. Jun 2012;153(6):1144-1147.

37. Woby SR, Urmston M, Watson PJ. Self-efficacy mediates the relation between painrelated fear and outcome in chronic low back pain patients. Eur J Pain. Oct 2007;11(7):711-718.

38. Polit D, Hungler B. Nursing Research: Principle and Method. 6th ed. Philadelphia: Lippincott Company; 1999. 
Table 1. Descriptive characteristics of the patients $(\mathrm{N}=21)$

\begin{tabular}{|c|c|}
\hline Gender, women, $\mathrm{n}$ & 8 \\
\hline Age, years, median (min, max) & $64(43,81)$ \\
\hline \multicolumn{2}{|l|}{ Diagnosis } \\
\hline STEMI & 10 \\
\hline NSTEMI & 11 \\
\hline PCI at hospital, $\mathrm{n}$ & 21 \\
\hline \multicolumn{2}{|l|}{ Grading of angina pectoris (CCS) } \\
\hline 0 & 15 \\
\hline 1 & 5 \\
\hline 2 & 1 \\
\hline \multicolumn{2}{|l|}{ Previous history of disease } \\
\hline Hypertension & 10 \\
\hline Arrhythmia & 0 \\
\hline Coronary artery disease & 1 \\
\hline Type 2 Diabetes & 3 \\
\hline \multicolumn{2}{|l|}{ Score on TSK-SV Heart } \\
\hline Median, (min, $\max )$ & $40(32,53)$ \\
\hline Attendance at exercise-based CR, $n$ & 12 \\
\hline \multicolumn{2}{|l|}{ Civil status, $n$} \\
\hline Married/cohabitant & 12 \\
\hline Living alone & 9 \\
\hline \multicolumn{2}{|l|}{ Professional employment, $\mathrm{n}$} \\
\hline Working & 8 \\
\hline
\end{tabular}


Retired

On sick leave

6

Continuous variables are presented as median (min-max), categorical data are presented as number. n, number; STEMI, ST-elevation myocardial infarction; NSTEMI, non-ST elevation myocardial infarction; PCI, percutaneous coronary intervention; CCS, Canadian Cardiovascular Society; TSK-SV Heart, Tampa Scale for Kinesiophobia Heart; CR, cardiac rehabilitation 
Table 2. The content analytic procedure as applied in this study, based on Graneheim and Lundman (Graneheim, 2004).

1. The sense of the whole

The transcribed interviews were read through in their entirety several times to get a sense of their content

2. Meaning units

The text was divided into meaning units, which comprised the words and sentences that were related to each other through their content

3. Condensed meaning units

The meaning units were condensed into shorter text that still contained the core of the meaning units.

4. Codes

Each condensed meaning unit was labelled with codes, in a process of abstraction interpreting the underlying meaning

5. Subthemes

All codes were then compared with each other, and those with similar content were sorted into subthemes.

6. Themes

The subthemes were condensed into a theme, based on the underlying meaning of the subthemes. 


\section{Figure legends}

Figure 1. Flow chart of included patients 


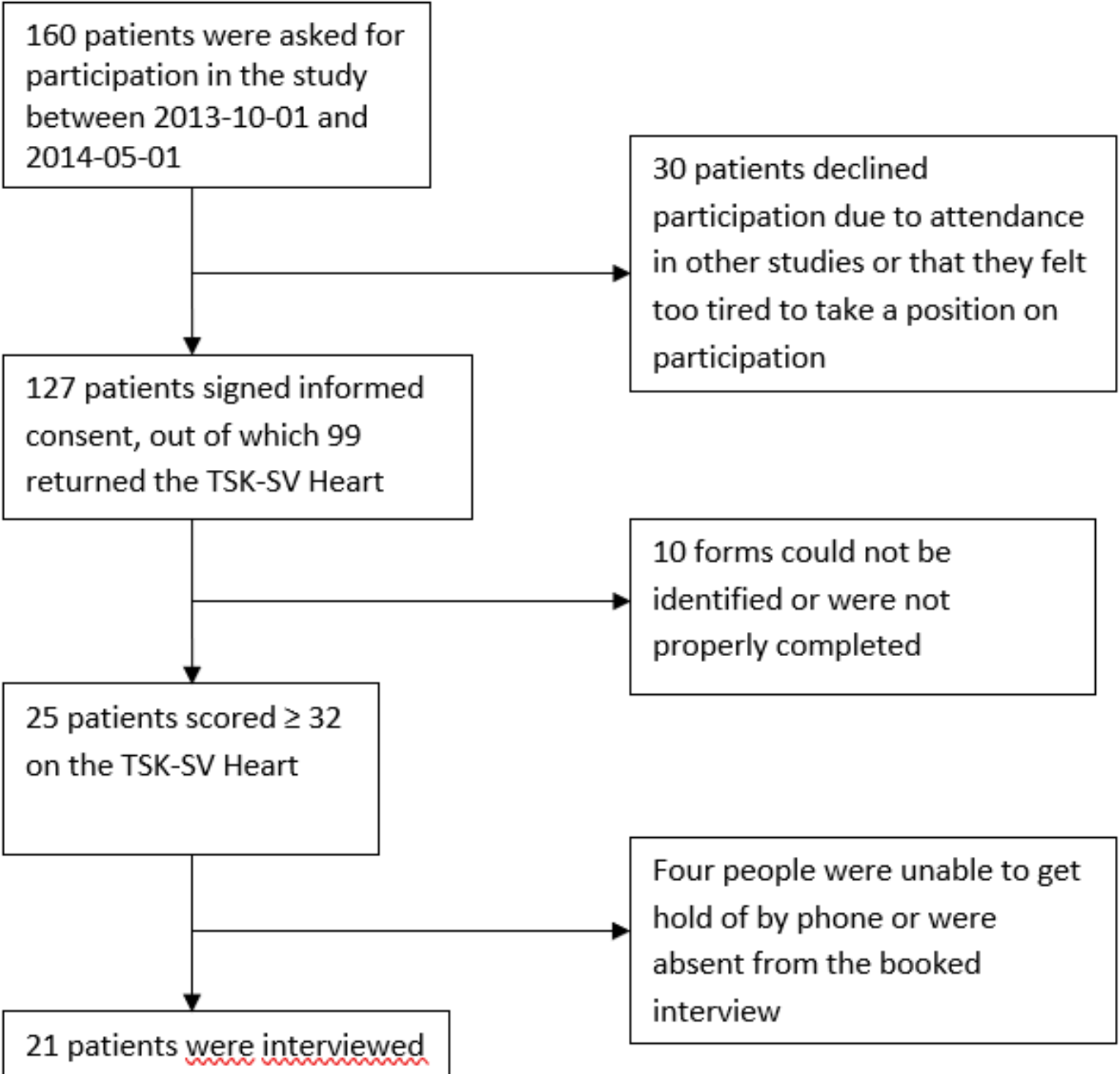

Figure 1. 


\section{Appendix}

\section{The main questions from the interview guide}

- How did you feel moving after having suffered a myocardial infarction?

- Describe a situation when you were physically active. How did you feel?

- Do you perform the same type of physical activities today as before the myocardial infarction?

- Have you experienced fear in relation to any movement after having suffered from the myocardial infarction? Can you give an example?

- Do you perceive any differences between you and a friend, without the diagnosis of a myocardial infarction, when it comes to performing physical activity and exercise?

- Do you perceive fear when participating in exercise-based cardiac rehabilitation?

- How did you perceive the information that you received from the health care professional regarding physical activity? 